\title{
Preparation and Characterization of Folate Conjugated Nanoparticles of Doxorubicin using PLGA-PEG-FOL Polymer
}

\section{Sai HS. Boddu1', R. Vaishya², J. Jwala², A. Vadlapudi², D. Pal ${ }^{2}$ and A.K. Mitra²*}

${ }^{1}$ Department of Pharmacy Practice, College of Pharmacy, The University of Toledo, 3000 Arlington Ave. Ohio 43614, USA

${ }^{2}$ Division of Pharmaceutical Sciences, School of Pharmacy, University of Missouri-Kansas City, 2464 Charlotte Street, Kansas City, MO 64108-2718, USA

\begin{abstract}
Purpose: This article describes the preparation and characterization of folate conjugated nanoparticles using poly(lactide-co-glycolide)-poly(ethylene glycol)-folate (PLGA-PEG-FOL) polymer for targeted delivery of anticancer agents.
\end{abstract}

Methods: PLGA-PEG-FOL was synthesized by coupling di-block copolymer (PLGA-PEG-NH ${ }_{2}$ ) with folic acid. PLGA-PEG-FOL polymer was characterized by ${ }^{1} \mathrm{H}$ NMR, GPC and FTIR. PLGA-PEG-FOL polymer was employed in the preparation of doxorubicin (DOX) loaded nanoparticles by double emulsion solvent evaporation (DESE), single emulsion solvent evaporation (SESE) and dialysis methods. Nanoparticles were characterized for size, morphology, entrapment efficiency, in vitro release and folate content. The presence of folate on nanoparticle surface was also confirmed using transmission electron microscopy. Qualitative uptake and cell viability studies were carried out in FOL receptor-positive ovarian cancer cells (SKOV3).

Results: DESE and SESE methods resulted in folate conjugated nanoparticles with an average size of $200 \mathrm{~nm}$ and entrapment efficiencies of 24.5 and $51.9 \%$ respectively. However, dialysis method resulted in microparticles with an average size of $2.5 \mu \mathrm{m}$. Folate conjugated nanoparticles exhibited higher uptake and cytotoxicity in SKOV3 cells in comparison with the pure DOX and unmodified nanoparticles.

Conclusion: PLGA-PEG-FOL can be utilized in the preparation of surface modified nanoparticles for targeted delivery of anticancer agents to FOL-receptor-positive cancer cells.

Keywords: PLGA-PEG-FOL; Doxorubicin; Nanoparticles; Cancer; Targeted delivery

Abbrevations: PLGA-PEG-FOL: Poly (Lactide-co-Glycolide)b-PolyEthylene Glycol)-Folate; FR: Folate Receptor; FA: Folic Acid; SESE: Single Emulsion Solvent Evaporation or O/W Emulsion Solvent Evaporation Method; DESE: Double Emulsion Solvent Evaporation or W/O/W Double Emulsion Solvent Evaporation Method; DOX: Doxorubicin; DOXNP: Doxorubicin Loaded Unmodified Nanoparticles; FDOXNP: Doxorubicin Loaded Folate Conjugated Nanoparticles; SKOV3 cells: Fol-Receptor-Positive Human Ovarian Cancer Cells; TEM: Transmission Electron Microscopy; ${ }^{1} \mathrm{HNMR}$ : Proton Nuclear Magnetic Resonance Spectroscopy; GPC: Gel Permeation Chromatography; FTIR: Fourier Transform Spectroscopy

\section{Introduction}

Nanoparticles are colloidal particulate systems with particle sizes ranging between 10-1000 $\mathrm{nm}$. During the last decade, polymeric nanoparticles have gained lot of attention due to their versatile properties including: long shelf stability, high drug loading capacity, and their ability to deliver both hydrophilic and hydrophobic drug molecules via peroral, transmucosal and inhalation routes $[1,2]$. They are made up of biocompatible and biodegradable polymers obtained from either natural (chitosan, albumin, sodium alginate and gelatin) or synthetic (poly (lactic acid), poly (D,L-glycolide), poly (lactide-coglycolide), poly (caprolactones) and poly (cyanoacrylates)) sources [3]. The selection of polymer depends on physicochemical properties of drug molecules to be included and duration of release desired [4]. Over the last two decades nanoparticulate systems have been successfully utilized for passive and active targeting of drugs. Passive targeting is achieved by modification of nanoparticulate surface using various hydrophilic linkers such as PolyEthylene Glycol (PEG), poloxamer, PolyEthylene Oxide (PEO), polysorbate and lauryl ethers [3]. These linkers prevent the uptake of nanoparticles by ReticuloEndothelial System (RES) and thereby increase the circulation time in blood [5].
These long-circulating nanoparticles accumulate in tumors cells due to their high microvascular permeability and defective lymphatic drainage. Active targeting helps in delivering the drug to the site of action while minimizing its exposure to non-target regions. Active targeting of nanoparticles can potentially increase the efficacy and reduce the toxicity of therapeutic agents [6]. This is achieved by conjugating the surface of nanoparticles using specific cell ligands. Cell targeting ligands can be classified into 3 types: small molecules (folate, biotin, galactose, glucose and mannose), small peptides (RGD), and proteins (transferrin and antibodies) [7-9]. Folic acid (FA) has been widely used in the delivery of anticancer agents due to its small size, low cost, high tumor tissue specificity and non-immunogenic nature [10]. FA linked nanocarriers have fairly high binding affinity to folate receptors (FR) expressed on tumor cells [11].

Various drug carriers such as liposomes [12], polymer conjugates, lipid nanoparticles [13], polymeric micelles [14] and nanoparticles [15] have been successfully linked to FA for targeted delivery of drugs to cancer cells. Folate linked liposomes and polymeric micelles are prepared from polymers that are covalently linked to targeting moiety. However, in case of nanoparticles these ligands are chemically

${ }^{*}$ Corresponding author: Ashim K. Mitra, Division of Pharmaceutical Sciences, School of Pharmacy, University of Missouri-Kansas City, 2464 Charlotte Street, Kansas City, MO 64108-2718, USA, Tel: 816-235-1615; Fax: 816-235-5779 E-mail: mitraa@umkc.edu

Received April 23, 2012; Accepted May 18, 2012; Published May 19, 2012

Citation: Boddu SHS, Vaishya R, Jwala J, Vadlapudi A, Pal D, et al. (2012) Preparation and Characterization of Folate Conjugated Nanoparticles of Doxorubicin using Plga-Peg-Fol Polymer. Med chem 2: 068-075. doi:10.4172/21610444.1000117

Copyright: (C) 2012 Boddu SHS et al. This is an open-access article distributed under the terms of the Creative Commons Attribution License, which permits unrestricted use, distribution, and reproduction in any medium, provided the original author and source are credited. 
conjugated after the nanoparticle preparation $[16,17]$. This approach is associated with significant loss of drug during the conjugation process. Moreover, introduction of multiple ligands on the surface becomes tedious. Alternative methods have been reported in the literature to overcome these disadvantages. Kim et al. developed cancer cell targeted nanoparticulate delivery system using Poly(L-lysine)-Poly(Ethylene Glycol)-Folate (PLL-PEG-FOL) conjugate. In this strategy, the positively charged PLL anchors on the surface of negatively charged PLGA nanoparticles [18]. PLL-PEG-FOL coated PLGA nanoparticles exhibited higher uptake in human nasopharyngeal epidermoid carcinoma (KB) cells as compared to unmodified nanoparticles. Recently, Interfacial Activity Assisted Surface Functionalization (IAASF) technique was utilized in the preparation of surface modified polymeric nanoparticles [19]. This method involves the addition of copolymer ligand to primary emulsion containing polymer and drug which then localizes and orients at the interface upon solvent evaporation. However, this technique may not be applicable for the delivery of hydrophilic molecules including proteins and peptides.

In this study we have proposed an alternative and relatively easy strategy for the preparation of surface modified nanoparticles for both hydrophilic and hydrophobic drug molecules. This study involves the use of Poly(Lactide-co-Glycolide)-Poly(Ethylene Glycol)-Folate (PLGA-PEG-FOL) conjugate for the preparation of nanoparticles. PLGA-PEG-FOL polymer was synthesized and characterized using ${ }^{1} \mathrm{H}$ NMR, GPC and FTIR. Further the ability of PLGA-PEG-FOL polymer to form folate surface modified nanoparticles was investigated using three different techniques. Doxorubicin (DOX), a chemotherapeutic agent widely used in the treatment of non-Hodgkin's lymphoma, Ewing sarcoma, multiple myeloma, acute leukemias, Wilm tumor, Kaposi sarcoma, and cancers of the lung, breast, adrenal cortex, ovary, and endometrium, was utilized in the preparation of nanoparticles [20,21]. The polarity of DOX was sufficiently varied and then entrapped in the nanoparticles using Double Emulsion Solvent Evaporation (DESE), Single Emulsion Solvent Evaporation (SESE) and dialysis methods. Nanoparticles were evaluated for entrapment efficiency, morphology, particle size and in vitro release. Presence of folate on the nanoparticle surface was confirmed by Transmission Electron Microscopy (TEM) studies. Qualitative and quantitative uptake studies were carried out in FOL receptor-positive ovarian cancer (SKOV3) cells.

\section{Materials and Methods}

\section{Materials}

PLGA polymers, i.e. PLGA 65:35 (d,l-lactide : glycolide), molecular weight 40,000-75,000 Da, polyvinyl alcohol (PVA), folic acid, dialysis tubing made of cellulose membrane, mouse anti-folic acid, goat antimouse IgG labeled with gold nanoparticles $(10 \mathrm{~nm})$ were procured from Sigma Chemicals (St Louis, MO). Resazurin dye was obtained from Biotium, Inc. (Hayward, CA). Penicillin, bovine serum and streptomycin were obtained from Invitrogen Corporation (Carlsbad, CA). DiMethyl Sulfoxide (DMSO) and dichloromethane were obtained from Fisher Scientific (Pittsburgh, PA). PEG-bis-amine, molecular weight $3.4 \mathrm{kDa}$ was obtained from Fluka Analytical, Germany.

\section{Synthesis of PLGA-PEG-FOL}

PLGA-PEG-FOL was synthesized as follows: 1) activation of PLGA, 2) conjugation of activated PLGA with PEG-bis-amine, and 3) conjugation of FA to PLGA-PEG.

\section{Step I: Activation of PLGA}

PLGA was activated with DCC and $N$-HydroxySuccinimide (NHS) in dichloromethane (molar ratio of DCC: NHS: PLGA = 2:2:1) under inert atmosphere for $24 \mathrm{~h}$. Activated PLGA was precipitated with icecold diethyl ether followed by filtration and freeze drying for $24 \mathrm{~h}$.

\section{Step II: Conjugation of activated PLGA with PEG-bis-amine}

Activated PLGA was dissolved in $1 \mathrm{~mL}$ of methylene chloride. In a separate flask, PEG-bis-amine was dissolved in methylene chloride and added to PLGA solution in a drop-wise manner (PLGA:PEG-bisamine::1:3). The reaction mixture was stirred under inert nitrogen atmosphere for $6 \mathrm{~h}$. The resulting solution was precipitated by the addition of ice-cold diethyl ether. The precipitated product, amineterminated di-block copolymer, PLGA-PEG-NH $\mathrm{NH}_{2}$ was filtered and dissolved in DMSO. The solution was dialyzed (MWCO: $7 \mathrm{kDa}$ ) against distilled water for $48 \mathrm{~h}$ to remove the unreacted PEG-bis amine and then freeze dried.

\section{Step III: Conjugation of FA to PLGA-PEG}

FA was activated with DiCyclohexylCarbodiimide (DCC). In a separate flask, PLGA-PEG- $\mathrm{NH}_{2}$ was dissolved in DMSO and added to activated FA in a drop-wise manner (PLGA-PEG$\left.\mathrm{NH}_{2}: \mathrm{FA}: \mathrm{DCC}=1: 2: 2.5\right)$. The reaction was performed under inert nitrogen atmosphere at room temperature for $12 \mathrm{~h}$. The solution was dialyzed (MWCO: $10 \mathrm{kDa}$ ) against distilled water for $48 \mathrm{~h}$ to remove the unreacted FA and freeze dried. The structure of PLGA-PEG-FOL was confirmed by ${ }^{1} \mathrm{H}$ NMR spectroscopy (VarianINOVA-400 MHz NMR spectrometer) in $\mathrm{d}_{6}$-DMSO. Chemical shifts $(\delta)$ were expressed in parts per million ( $\mathrm{ppm}$ ) relative to the NMR solvent signal ( $\left.\mathrm{d}_{6}-\mathrm{DMSO}\right)$ using tetramethylsilane as an internal standard. Amount of FA conjugated to PLGA-PEG-FOL was determined using a UV-visible calibration curve of FA generated in DMSO at $340 \mathrm{~nm}$.

\section{Characterization of PLGA-PEG-FOL by Gel Permeation Chromatography (GPC)}

The weight average molecular weight of PLGA-PEG-FOL was determined by GPC. A Waters 410 Diffraction Refractometer and Waters Styragel HR4E column $(7.8 \times 300 \mathrm{~mm})$ column were used in the analysis. The mobile phase (dimethylformamide) was delivered by a Waters 515 HPLC pump. A standard curve was obtained by using PEG standards in the size range of 100-15,000 Da (Polysciences, PA).

\section{Characterization of PLGA-PEG-FOL by FTIR}

The presence of amide linkages in PLGA-PEG-FOL was confirmed with Perkin-Elmer Spectrum One Fourier Transform Infrared Spectrophotometer (FTIR) with a resolution of $4 \mathrm{~cm}^{-1}$ in the ATR sampling mode. Approximately $10 \mathrm{mg}$ of control (a mixture of PLGA, PEG-bis-amine and FA dissolved in DMSO and dialyzed against distilled water for $48 \mathrm{~h}$ and freeze dried) or polymer (PLGA-PEG-FOL) was placed on the horizontal face of the internal reflectance crystal. A diamond crystal with a transmission range of $400-650 \mathrm{~cm}^{-1}$ was used in the experiment.

\section{Development of folate conjugated nanoparticles}

Double emulsion solvent evaporation method (DESE method): Briefly, $2 \mathrm{mg}$ of DOX was dissolved in $400 \mu \mathrm{L}$ of distilled deionized water and added to $3 \mathrm{~mL}$ of dichloromethane consisting of PLGA (25 $\mathrm{mg}$ ). A primary W/O emulsion was obtained by sonication (Fisher 100 Sonic Dismembrator, Fisher Scientific) at a constant power output of $55 \mathrm{~W}$ for $2 \mathrm{~min}$. The primary emulsion was further mixed with $2 \mathrm{~mL}$ of 
dichloromethane consisting of $75 \mathrm{mg}$ PLGA-PEG-FOL and vortexed vigorously for $2.5 \mathrm{~min}$. The organic phase was slowly mixed with an aqueous solution containing $2.5 \%$ PVA under continuous stirring. A W/O/W emulsion was obtained by sonication at a constant power output of $55 \mathrm{~W}$ for $5 \mathrm{~min}$. The sample was kept in an ice bath during sonication to prevent any overheating of the emulsion. It was stirred gently at room temperature for $12 \mathrm{~h}$. Subsequently, the nanoparticle suspension was exposed to vacuum for $1 \mathrm{~h}$ to ensure complete removal of organic solvents. PVA residue was removed by washing nanoparticles three times with distilled water. The resultant suspension was centrifuged at 22,000 g for $60 \mathrm{~min}$. Nanoparticles formed were freeze-dried for $48 \mathrm{~h}$ in the presence of $2 \%$ trehalose.

Single emulsion solvent evaporation method (SESE method): DOX extraction in methylene chloride was carried out as per the previously published method with minor modification [22]. Two milligrams of DOX was dissolved in $5 \mathrm{~mL}$ of $0.1 \mathrm{M}$ sodium carbonate and sodium bicarbonate buffer ( $\mathrm{pH}$ adjusted to 8.6). The aqueous phase was shaken with $50 \mathrm{~mL}$ of methylene chloride for $24 \mathrm{~h}$ at $25^{\circ} \mathrm{C}$. Methylene chloride solution was evaporated under vacuum until the final volume of $5 \mathrm{~mL}$ was reached. One hundred milligrams of PLGAPEG-FOL was added to the methylene chloride solution. The organic phase was slowly mixed with an aqueous solution containing $2.5 \%$ PVA under continuous stirring. An $\mathrm{O} / \mathrm{W}$ type emulsion was obtained by sonication at a constant power output of $55 \mathrm{~W}$ for $5 \mathrm{~min}$ [23]. The sample was kept in an ice bath during sonication to prevent any overheating of the emulsion and stirred gently at room temperature for $12 \mathrm{~h}$. Subsequently, nanoparticle suspension was exposed to vacuum for $1 \mathrm{~h}$ to ensure complete removal of organic solvents. PVA residue was removed by washing nanoparticles thrice with distilled water. The resulting suspension was centrifuged at 22,000 g for $60 \mathrm{~min}$. The nanoparticles formed were freeze-dried for $48 \mathrm{~h}$ in the presence of $2 \%$ trehalose. Unmodified nanoparticles were also prepared in the similar manner using PLGA 65:35 and used as control as needed.

Dialysis method: PLGA-PEG-FOL nanoparticles were prepared by dialysis method without the incorporation of any surfactants. DOX was neutralized with a $2 \mathrm{~mol}$ excess of TriEthylAmine (TEA) in $2 \mathrm{~mL}$ of DMSO. Briefly, $2 \mathrm{mg}$ of DOX (after TEA treatment) and $100 \mathrm{mg}$ of PLGA-PEG-FOL were dissolved in $3 \mathrm{~mL}$ of DMSO and vortexed for 10 min. The solution was introduced into a dialysis bag (MWCO: $6.5 \mathrm{kDa}$ ) and dialyzed against distilled water with continuous stirring at room temperature for $24 \mathrm{~h}$ with the water replaced every $3 \mathrm{~h}$. The resulting suspension was centrifuged at 22,000 g for $60 \mathrm{~min}$. Nanoparticles formed were freeze-dried for $48 \mathrm{~h}$ in the presence of $2 \%$ trehalose.

\section{Entrapment efficiency}

Two milligrams of freeze dried nanoparticles were dissolved in DMSO and their DOX content was analyzed using a microplate reader (DTX 880 Series Multimode Detector, Multimode Detection Software, Beckman Coulter, Inc, CA) at $485 \mathrm{~nm}$ (excitation wavelength) and 595 $\mathrm{nm}$ (emission wavelength). Entrapment efficiency was calculated using Equation 1 [24]. All experiments were conducted in triplicate.

Entrapment efficiency $\%=$

(amount of drug remained in nanoparticles)

$$
\text { (initial drug amount) } \times 100
$$

\section{Morphology}

TEM (Philips CM12 STEM, Hillsboro, OR) was utilized for examining the morphology of nanoparticles. A drop of solution containing nanoparticles was placed on a carbon-coated copper grid and excess fluid was removed with a piece of filter paper. The sample was stained with a $2 \%$ phosphotungstic acid solution and excess solution was removed using a filter paper. TEM images were taken after the sample was completely dried.

\section{Particle size and zeta-potential measurement}

Particle size and surface charge analysis of nanoparticles was performed using a Zeta Phase Analysis Light Scattering (PALS) UltraSensitive Zeta Potential Analyzer instrument (Brookhaven Instruments, Holtsville, NY). Nanoparticles were suspended in double distilled deionized water to give optimum signal intensity. The particle size and zeta-potential of each sample was determined using 3 independent measurements.

\section{Characterization of folate linked nanoparticles by TEM}

The functional presence of folate ligand on the nanoparticle surface was determined by TEM as per the previously published method with minor modifications [25]. Folate conjugated nanoparticles were initially incubated with $10 \%$ bovine serum albumin solution in PBS for $1 \mathrm{~h}$ and then incubated with mouse anti-FA monoclonal antibody for 1 h. Unbound mouse anti-folic acid monoclonal antibody was removed by washing the nanoparticles with PBS. Nanoparticles were then incubated with $10 \mathrm{~nm}$ gold particles coated with goat anti-mouse IgG. Unbound gold particles were removed by washing the nanoparticles with PBS solution. A drop of solution containing nanoparticles was placed on a carbon-coated copper grid and excess fluid was removed with a piece of filter paper. TEM images were taken after the sample was completely dried.

\section{Determination of folate content on the surface of nanoparticles}

The amount of folate present on the surface of nanoparticles prepared by SESE, DESE or dialysis methods was determined by UV spectrophotometer. Analysis was carried out in $\mathrm{CH}_{2} \mathrm{Cl}_{2} / \mathrm{DMSO}$ (1:4) solvent. The nanoparticles were evaluated by measuring the absorbance of the sample at $358 \mathrm{~nm}$ (folic acid $\varepsilon=15,760 \mathrm{M}^{-1} \mathrm{~cm}^{-1}$ ) [26].

\section{In vitro drug release}

Drug loaded nanoparticles $(5 \mathrm{mg}$ ) were dispersed in $1 \mathrm{~mL}$ of isotonic phosphate buffer saline (IPBS) at $\mathrm{pH} 7.4$ and subsequently introduced into dialysis bags (MWCO - $6275 \mathrm{~g} / \mathrm{mole}$ ) [27]. The dialysis bags were introduced into vials containing $10 \mathrm{ml}$ of IPBS and $0.025 \%$ $\mathrm{w} / \mathrm{v}$ sodium azide to avoid microbial growth and $0.02 \%(\mathrm{w} / \mathrm{v})$ Tween 80 to maintain sink conditions $[28,29]$. The vials were placed in a shaker bath at $37 \pm 0.5^{\circ} \mathrm{C}$ and 60 oscillations per minute. At regular time intervals $200 \mu \mathrm{L}$ of samples were withdrawn and replaced with equal volumes of fresh buffer. Samples were analyzed as mentioned above. Experiments were conducted in triplicate.

\section{Cell culture studies}

FOL-receptor-positive human ovarian cancer cells (SKOV3 cells) were obtained from ATCC (American Type Culture Collection, Manassas, VA, USA). These cells were grown in T-75 flasks with DMEM medium supplemented with $10 \%$ fetal bovine serum and $1 \%$ penicillin-streptomycin at $37^{\circ} \mathrm{C}$ in a humidified incubator with $5 \%$ $\mathrm{CO}_{2}$. The medium was changed every alternate day. Trypsinization procedure was carried out for cell harvesting and sub-cultivation after 80 to $90 \%$ confluence. 


\section{Qualitative uptake studies}

SKOV3 cells were seeded in a chambered cover glass system (LabTek, Nunc International Co., Naperville, IL, USA) and incubated with pure DOX, DOX loaded unmodified nanoparticles (DOXNP), DOX loaded PLGA-PEG-FOL nanoparticles (FDOXNP), and FDOXNP in presence of excess FA $(\sim 1 \mathrm{mM})$ for $30 \mathrm{~min}$ in DPBS. A DOX concentration equivalent to $10 \mu \mathrm{g} / \mathrm{mL}$ was maintained in the solutions. Following incubation, the cells were washed 3 times to remove uninternalized DOX and then exposed to $4 \%$ buffered paraformaldehyde for $20 \mathrm{~min}$ at $4^{\circ} \mathrm{C}$, rinsed thrice with DPBS and mounted on glass slides using mounting gel. Slides were observed under confocal laser fluorescence microscope (Olympus FV300 confocal laser scanning unit coupled to an Olympus BX61 upright microscope (Center Valley, PA)). Pictures were processed by Fluoview ${ }^{\text {Tw }}$ software and edited by Adobe Photoshop CS3 (Adobe Systems Inc., San Jose, CA, USA).

\section{Quantitative uptake studies}

SKOV3 cells were washed three times with Dulbecco's phosphatebuffered saline (DPBS), $\mathrm{pH} 7.4$, containing $0.03 \mathrm{mM} \mathrm{KCl}, 130 \mathrm{mM}$ $\mathrm{NaCl}, 1 \mathrm{mM} \mathrm{CaCl}, 7.5 \mathrm{mM} \mathrm{Na}_{2} \mathrm{HPO}_{4}, 1.5 \mathrm{mM} \mathrm{KH} \mathrm{PO}_{4}, 0.5 \mathrm{mM}$ $\mathrm{MgSO}_{4}$, and $5 \mathrm{mM}$ glucose to remove endogenous folates bound to folate receptors on the cell surface. Uptake studies were carried out in DPBS, pH 7.4. Uptake was initiated by the addition of $100 \mu \mathrm{g} / \mathrm{mL}$ of pure DOX, DOXNP, FDOXNP or FDOXNP in presence of excess FA $(\sim 1 \mathrm{mM})$ for $1 \mathrm{~h}$. After incubation cells were rinsed 3 times with $1 \mathrm{~mL}$ of ice-cold stop solution ( $210 \mathrm{mM} \mathrm{KCl}, 2 \mathrm{mM} \mathrm{HEPES})$, to arrest uptake. After each wash cells were centrifuged and separated. Cells were then solubilized in $0.5 \mathrm{~mL}$ of $1 \%$ Triton-X solution. DOX concentration was measured with the help of fluorescence spectrophotometer at $485 \mathrm{~nm}$ (excitation wavelength) and $595 \mathrm{~nm}$ (emission wavelength) [30,31].

\section{Cell viability studies}

Cells were harvested and seeded on 96 well plates (Costar, Chicago, IL) at a density of 10,000 cells $/ 100 \mu \mathrm{L}$ of medium. The plates were incubated at $37^{\circ} \mathrm{C}$ for $24 \mathrm{~h}$ to allow the exponential growth of cells. The medium was replaced on alternate days. The cells were incubated with pure DOX, DOX loaded unmodified nanoparticles (DOXNP) or DOXloaded PLGA-PEG-FOL nanoparticles (FDOXNP) in concentrations ranging from $0-10 \mu \mathrm{M}$. Vehicle without drug or blank nanoparticles was used as control [32]. Cells were incubated for $48 \mathrm{~h}$ and drug solutions were aspirated and then $100 \mu \mathrm{L}$ of resazurin dye solution was added to each well. The plate was incubated for $1 \mathrm{~h}$ at $37^{\circ} \mathrm{C}$ and amount of absorbance in each well was measured at $600 \mathrm{~nm}$. Resazurin is a blue colored compound and turns pink upon oxidation in presence of viable cells. The absorbance of sample reflects the number of viable cells [33]. Statistical significance was tested using the student $t$-test at $\left({ }^{*} \mathrm{p}<0.05\right)$.

\section{Results and Discussion}

Use of intravenously administered antineoplastic agents presents the possibility of severe side-effects and toxicity [34]. Moreover, cancer cells express high levels of efflux proteins including P-gp and MRP which restrict the permeation of chemotherapeutic agents. Active targeting helps in delivering the toxic anticancer agents to the site of action and minimizes its exposure to non-target regions. Active targeting of nanoparticles can potentially increase the efficacy and reduce the toxicity of therapeutic agents [6]. Several targeting ligands such as folate, biotin, galactose, glucose, mannose, and RGD peptide have been reported in literature $[7,8,9]$. Folic acid (FA) is widely used in the delivery of anticancer agents due to its small size, low cost, high tumor tissue specificity and non-immunogenic nature
[10]. In the present study we have proposed a relatively easy strategy for the preparation of folate conjugated PLGA nanoparticles for both hydrophilic and hydrophobic drug molecules. The biodegradable copolymer, PLGA-PEG-FOL, was successfully synthesized according to a published procedure with minor modifications $[14,24]$. On a molar ratio basis the conjugation of folate to PLGA-PEG was found to be 8.15 $\mu \mathrm{mol}$ of folate/gm of polymer. Two different strategies were employed to increase the folate conjugation to diblock copolymer PLGA-PEG. In the first strategy, reaction time of step III was increased from 0.5 to 4.0 days. However, no significant difference in the folate conjugation was observed after 4.0 days. In the second strategy, the reaction in step III was terminated after $12 \mathrm{~h}$ and the PLGA-PEG-FOL polymer was purified and freeze dried. The freeze dried polymer was again used in the conjugation of FA to unreacted PEG groups. After $12 \mathrm{~h}$ the reaction was terminated and the polymer sample was purified, freeze dried and analyzed for folate content. Surprisingly, the conjugation percentage of folate was increased by 3.5 fold. On a molar ratio basis, the conjugation of folate to PLGA-PEG was found to be $28.05 \mu \mathrm{mol}$ of folate/gm of polymer. PLGA-PEG-FOL polymer was characterized by NMR, FTIR and GPC. Chemical shifts $(\delta)$ were expressed in parts per million (ppm) relative to the NMR solvent signal ( $\mathrm{d}_{6}$-DMSO) with tetramethylsilane as an internal standard. Figure 1 demonstrates various proton peaks associated with PLGA-PEG-FOL polymer. Small peaks at 6.6, 7.6 and $8.7 \mathrm{ppm}$ may be due to the aromatic protons associated with folate. This reveals the coupling of folate to PLGA-PEG via NHS/DCC mediated reaction [35]. The peak at $3.6 \mathrm{ppm}$ is due to $-\mathrm{CH}_{2}$ - protons of PEG block. The peaks at 1.6 and $5.2 \mathrm{ppm}$ are due to $-\mathrm{CH}_{3}$ and $-\mathrm{CH}$ - protons of PLA block. The peak at $4.8 \mathrm{ppm}$ belongs to the $-\mathrm{CH}_{2}$ - protons of PGA block. PLGA-PEG-FOL polymer was further characterized for the number average molecular weight $\left(M_{n}\right)$, weight average molecular weight $\left(\mathrm{M}_{\mathrm{w}}\right)$ and polydispersity values were measured using GPC. The $M_{n}$ and $M_{w}$ of PLGA-PEG-FOL were found to be 18,482 and 37,148.82 Da respectively with a polydispersity of 2.01. The GPC curve exhibited a single peak that was eluted at a retention time of $7.42 \mathrm{~min}$ (Figure 2). The total molecular weight of PLGA-PEG-FOL was found to be slightly less than the molecular weight of individual blocks (PLGA, PEG, and FA). This may be due to slight degradation of PLGA during the dialysis process for purification. FTIR studies were carried out to confirm the presence of amide linkage in polymer. Characteristic FTIR absorption bands of folate in control or polymer are observed at 1453 and 1605 $\mathrm{cm}^{-1}$ (Figure 3). In control or polymer, the bands at 1453 and 1606 $\mathrm{cm}^{-1}$ may be due to the stretching vibrations of $\mathrm{C}=\mathrm{C}$ in the backbone of the aromatic ring present in folic acid [36]. The most significant FTIR

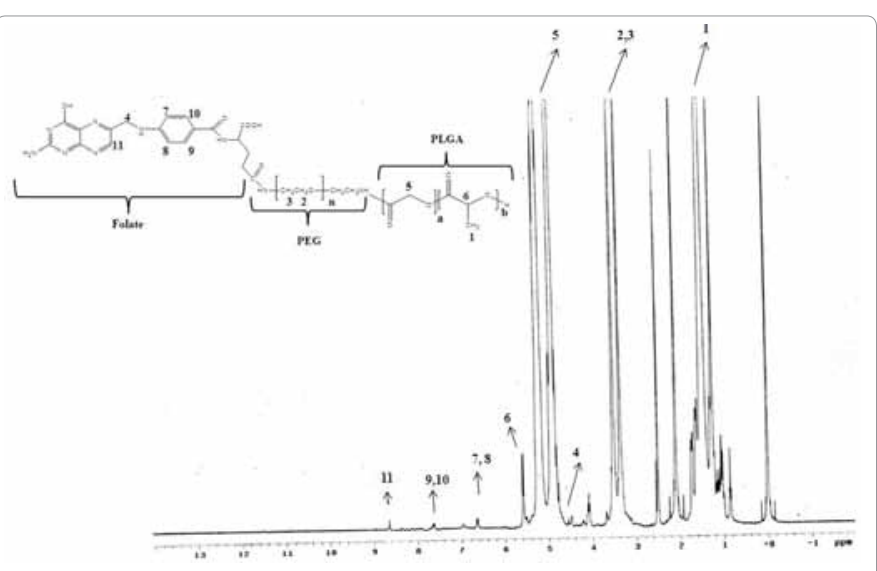

Figure 1: ${ }^{1} \mathrm{H}$ NMR spectrum of PLGA-PEG-FOL. 
absorption peak in PLGA-PEG-FOL polymer is due to the presence of - $\mathrm{CONH}$ - linkage. The carbonyl $(\mathrm{C}=\mathrm{O})$ and amine $(\mathrm{N}-\mathrm{H})$ groups present in the amide linkage exhibited bands at 1621 and $1568 \mathrm{~cm}^{-1}$ respectively [37,38]. However, these bands for amide linkage were absent in the control sample.

PLGA-PEG-FOL polymer was utilized in the preparation of nanoparticles using DESE, SESE or dialysis methods. DOX $\mathrm{HCl}$ was used for the preparation of nanoparticles by DESE method. While neutral form of DOX was utilized in the preparation of nanoparticles by SESE and dialysis methods. The DOX molecule contains three ionizable groups at $\mathrm{C}_{6}$ (phenol group), $\mathrm{C}_{11}$ (phenol group) and $\mathrm{C}_{3}$. (amine group) (Figure 4). At pH 8.6, DOX exists in its neutral form and can be extracted into the organic phase [22]. DOX concentration in the organic phase was measured using a fluorescence spectrophotometer. Approximately $96.8 \%$ of DOX is extracted into methylene chloride from aqueous phase consisting of $0.1 \mathrm{M}$ sodium carbonate and sodium bicarbonate buffer ( $\mathrm{pH}$ adjusted to 8.6). DOX nanoparticles of $\sim 200$ $\mathrm{nm}$ were successfully prepared by single and double emulsion solvent evaporation methods. However, dialysis method resulted in the formation of microparticles of $\sim 2.5 \mu \mathrm{m}$ (Figure 5). This may be due to the absence of surfactants and sonication process which play an important role in controlling the particles size. The experimental values of particle size, polydispersity and zeta-potential values of nanoparticles were shown in Table 1. The size and morphology of nanoparticles were confirmed by TEM (Figure 6). Both unmodified as well as folate conjugated nanoparticles exhibited negative zeta potential due to the

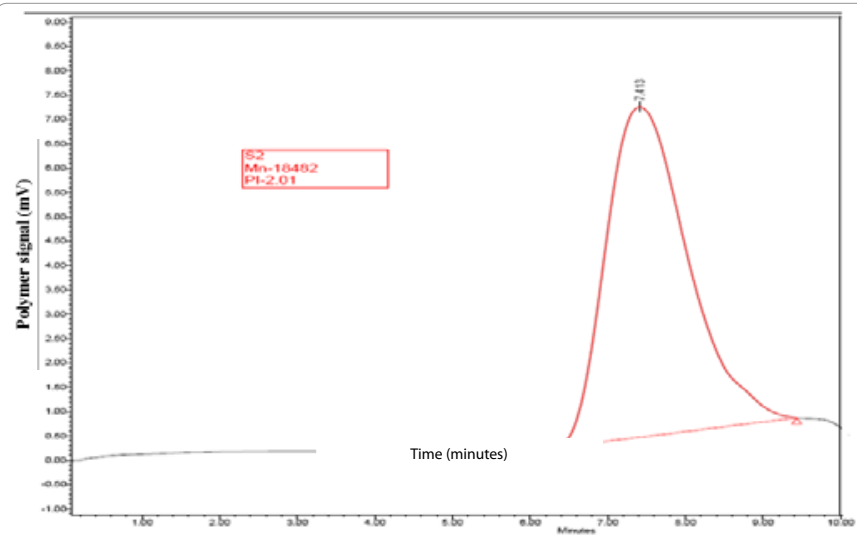

Figure 2: Gel permeation chromatography of PLGA-PEG-FOL polymer.

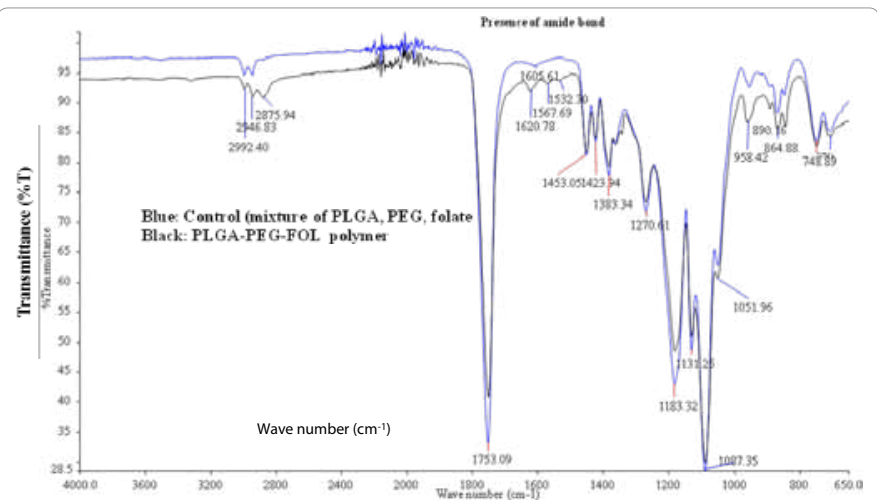

Figure 3: FTIR absorption peaks of control (Blue) and PLGA-PEG-FOL polymer (Black).

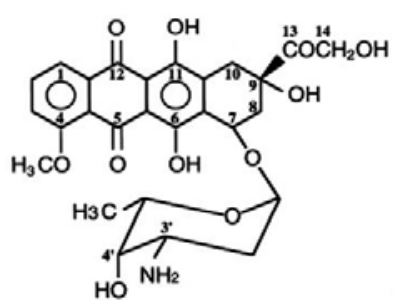

Figure 4: Structure of doxorubicin

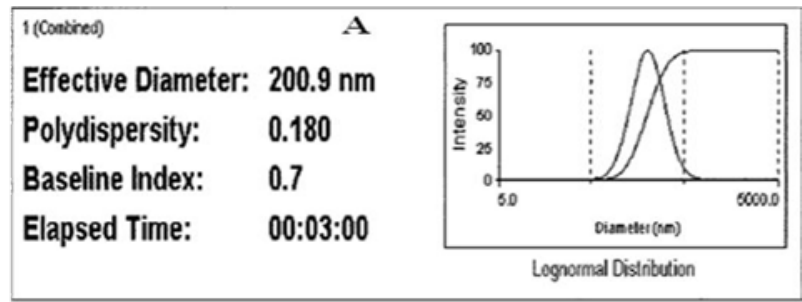

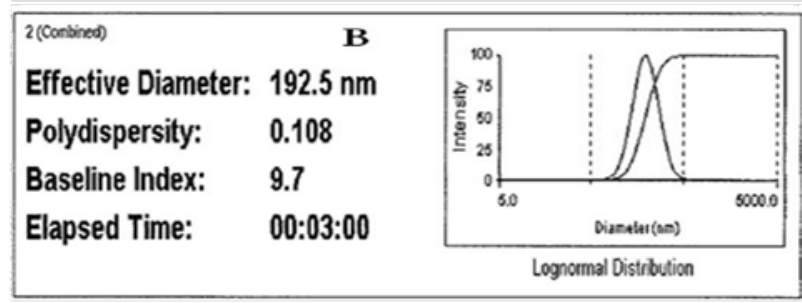

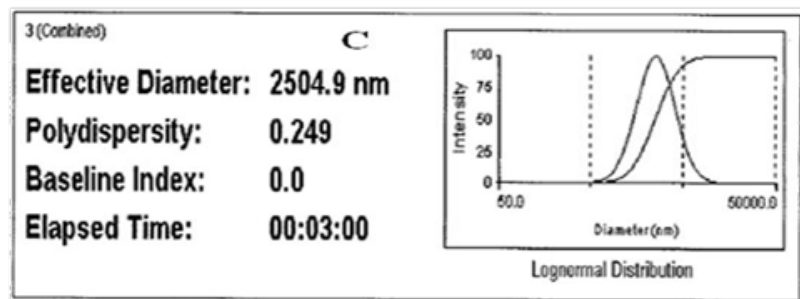

Figure 5: Particle size distribution curves of nanoparticles (A) PLGA-PEGFOL nanoparticles prepared by O/W emulsion method, (B) PLGA-PEG-FOL nanoparticles prepared by W/O/W double emulsion solvent evaporation method, (C) PLGA-PEG-FOL nanoparticles prepared by dialysis method.

presence of terminal carboxylic groups in the polymer [32]. Folate conjugated nanoparticles had smaller negative zeta potential values which may be due to the presence of positively charged amine groups in FA. SESE method resulted in higher DOX entrapment compared to DESE and dialysis methods. Entrapment efficiencies of DOX using DESE, SESE and dialysis methods were found to be $24.5,51.9$, and $32.6 \%$ respectively (Table 2 ). A decrease in affinity of neutral DOX molecule towards external aqueous phase during emulsification step might have resulted in higher entrapment efficiency by SESE method.

Folate present on the surface of nanoparticles was quantitatively estimated by UV spectroscopy respectively. Ghost nanoparticles were used for quantitative analysis of folate. The amount of folate on the surface of nanoparticles prepared by DESE, SESE and dialysis methods were found to be 3.57, 4.08 and $7.0 \mu \mathrm{mol}$ of folate/gm of nanoparticles respectively (Table 2). The microparticles were not further characterized. The functional presence of folic acid on the surface of nanoparticles was studied using transmission electron microscopy. Folate conjugated nanoparticles were incubated with anti-folic acid antibody and then with gold-labeled secondary antibody $(10 \mathrm{~nm})$. As seen in Figure 7, gold probes were found to bind folate conjugated 
nanoparticles. Moreover the folate conjugated nanoparticles were $\sim 200 \mathrm{~nm}$. In vitro release studies were carried out for the nanoparticles prepared form SESE and DESE methods. Irrespective of the preparation method a biphasic release pattern was observed from the nanoparticles. However, the nanoparticles prepared by using SESE method showed a significantly lower burst release. The duration of drug release from nanoparticles prepared by SESE and DESE methods were found to be 144 and $96 \mathrm{~h}$ respectively (Figure 8 ). This may be attributed to the better arrangement of DOX inside the PLGA matrix as a free base.

Nanoparticles prepared from SESE method were further used for assessing the qualitative and quantitative uptake studies in SKOV3 cells as they overexpress folate receptors. Qualitative uptake of DOX from pure drug solution, Unconjugated Nanoparticles (DOXNP), Folate Conjugated Nanoparticles (FDOXNP) and FDOXNP in presence of folic acid was carried out with confocal microscopy in SKOV3 cells. FDOXNP exhibited higher fluorescence intensity relative to free DOX and DOXNP (Figure 9). Fluorescence intensity was reduced in the presence of excess folic acid suggesting the uptake of nanoparticles via folate receptor. This indicates that FDOXNP enter the cells via folate receptor. Quantitative uptake of DOX from pure drug solution, UnConjugated Nanoparticles (DOXNP), Folate Conjugated Nanoparticles (FDOXNP) and FDOXNP in presence of FA was carried out using a fluorescence spectrophotometer in SKOV3 cells. FDOXNP exhibited higher uptake relative to free DOX and DOXNP (Figure 10). Uptake of DOX from FDOXNP was reduced in the presence of excess FA suggesting the uptake of nanoparticles is mediated via folate receptor. FDOXNP exhibited approximately four times higher uptake compared to pure DOX. Cytotoxicity studies of DOX formulations (DOX in solution, DOXNP and FDOXNP) were carried out in SKOV3 cells.

\begin{tabular}{|c|c|c|c|c|}
\hline $\begin{array}{l}\text { Polymer } \\
\text { used }\end{array}$ & $\begin{array}{l}\text { Preparation } \\
\text { Method }\end{array}$ & $\begin{array}{l}\text { Particle size } \\
(\mathbf{n m})\end{array}$ & Polydispersity & $\begin{array}{c}\text { Zeta } \\
\text { potential } \\
(\mathrm{mV})\end{array}$ \\
\hline PLGA & $\begin{array}{c}\mathrm{O} / \mathrm{W} \text { emulsion } \\
\text { solvent evaporation } \\
\text { method }\end{array}$ & $209.1 \pm 1.0$ & 0.050 & $-23.96 \pm 1.2$ \\
\hline \multirow{3}{*}{$\begin{array}{l}\text { PLGA- } \\
\text { PEG-FOL }\end{array}$} & $\begin{array}{c}\text { O/W emulsion } \\
\text { solvent evaporation } \\
\text { method }\end{array}$ & $200.9 \pm 0.1$ & 0.180 & $-8.96 \pm 1.1$ \\
\hline & $\begin{array}{c}\text { W/O/W double } \\
\text { emulsion solvent } \\
\text { evaporation method }\end{array}$ & $192.5 \pm 4.1$ & 0.108 & $-15.2 \pm 2.7$ \\
\hline & Dialysis method & $2504.9 \pm 208.5$ & 0.249 & $-14.46 \pm 1.3$ \\
\hline
\end{tabular}

PLGA-PEG-FOL: poly(lactide-co-glycolide)-b-poly(ethylene glycol)-folate

Table 1: Particle size of nanoparticles prepared by various methods using PLGAPEG-FOL polymer.

\begin{tabular}{|c|c|c|}
\hline Preparation Methoda & $\begin{array}{l}\text { Entrapment } \\
\text { efficiency } \\
\text { (mean } \pm \text { SEM) }\end{array}$ & $\begin{array}{l}\text { Amount of folate on } \\
\text { the surface of nanoparticles } \\
\text { ( } \mu \mathrm{M} \text { of folic acid/gm of } \\
\text { nanoparticles) }\end{array}$ \\
\hline $\begin{array}{l}\text { O/W emulsion solvent } \\
\text { evaporation method }\end{array}$ & $51.9 \pm 2.1$ & $4.08 \pm 0.9$ \\
\hline $\begin{array}{l}\text { W/O/W double emulsion } \\
\text { solvent evaporation } \\
\text { method }\end{array}$ & $24.5 \pm 1.4$ & $3.57 \pm 0.5$ \\
\hline Dialysis method & $32.6 \pm 2.4$ & $7.0 \pm 1.6$ \\
\hline
\end{tabular}

Table 2: Entrapment efficiency and folate content of nanoparticles prepared by various methods using PLGA-PEG-FOL polymer.

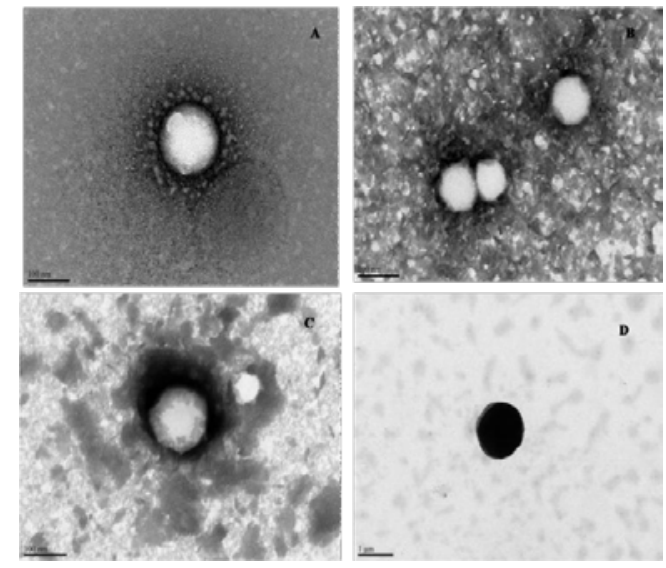

Figure 6: Transmission electron microscopy images of doxorubicin loaded folate conjugated nanoparticles (A) DOXNP, (B) FDOXNP prepared by W/O/W double emulsion solvent evaporation method, (C) FDOXNP prepared by O/W emulsion solvent evaporation method, (D) FDOXNP prepared by dialysis method.

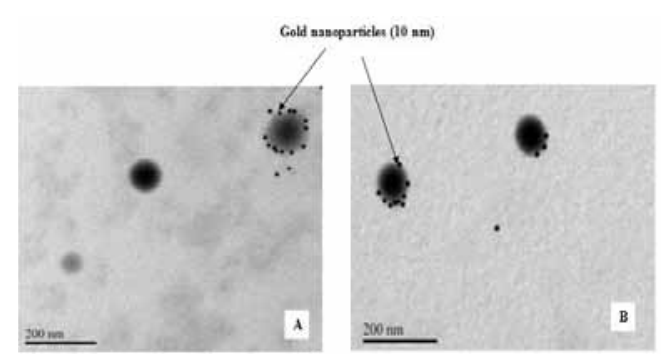

Figure 7: Transmission electron microscopy studies demonstrating the functional presence of folic acid on nanoparticles (A) PLGA-PEG-FOL nanoparticles prepared by O/W emulsion/solvent evaporation method, (B) PLGA-PEG-FOL nanoparticles prepared by W/O/W double emulsion solvent evaporation method.

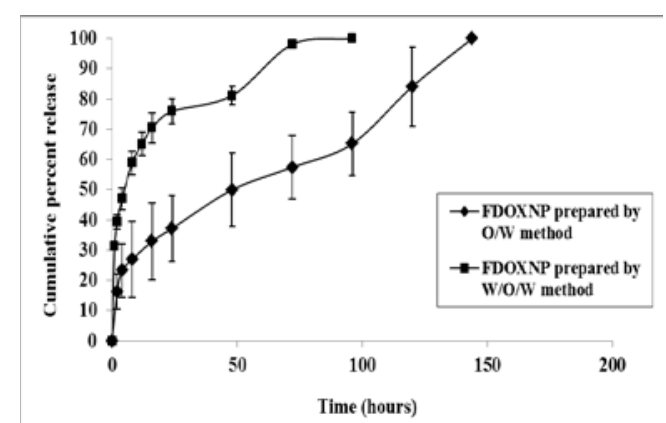

Figure 8: Percent cumulative release profiles of DOX from PLGA-PEG-FOL nanoparticles prepared by $\mathrm{O} / \mathrm{W}$ emulsion/solvent evaporation method $(n=3)$ and $\mathrm{W} / \mathrm{O} / \mathrm{W}$ double emulsion solvent evaporation method $(n=3)$. Error bars represent the standard error of mean (S.E.M).

At concentrations ranging from $0-10 \mu \mathrm{M}$, FDOXNP exhibited higher cytotoxicity in SKOV3 cells expressing folate as compared to free DOX or DOXNP (Figure 11). DOX is a well known substrate for multidrug resistant (MDR1) efflux pumps which are highly expressed on SKOV3 cells [39]. These efflux pumps lower the entry of DOX into SKOV3 cells [40]. However, FDOXNP enter the cells via folate receptors on the surface of SKOV3 cells. PEG acts as a linker between PLGA and folate moiety and helps in the binding of FA to folate receptors highly expressed on the surface of SKOV 3 cells. 
Citation: Boddu SHS, Vaishya R, Jwala J, Vadlapudi A, Pal D, et al. (2012) Preparation and Characterization of Folate Conjugated Nanoparticles of Doxorubicin using Plga-Peg-Fol Polymer. Med chem 2: 068-075. doi:10.4172/2161-0444.1000117
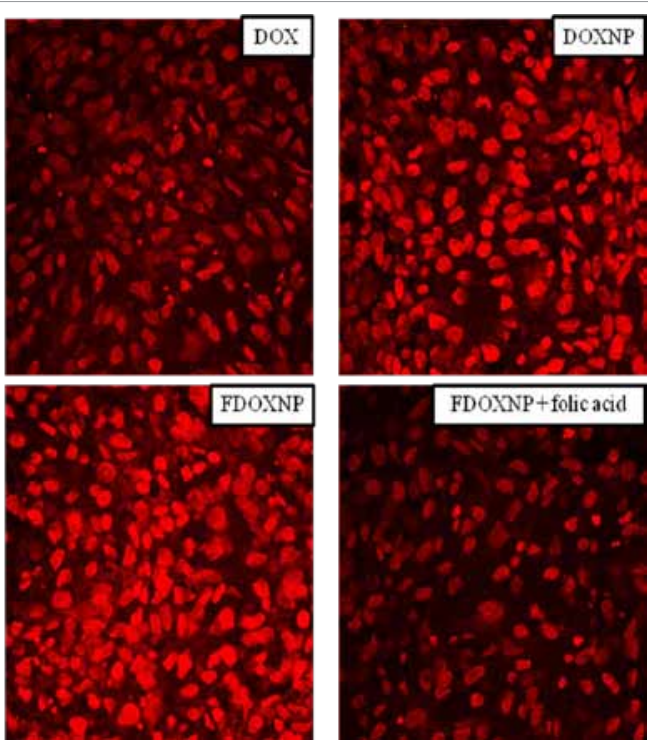

Figure 9: Qualitative uptake of DOX in SKOV3 cells using pure DOX, DOXNP (doxorubicin loaded unmodified nanoparticles), FDOXNP (doxorubicin loaded folate conjugated nanoparticles) and FDOXNP in presence of folic acid.

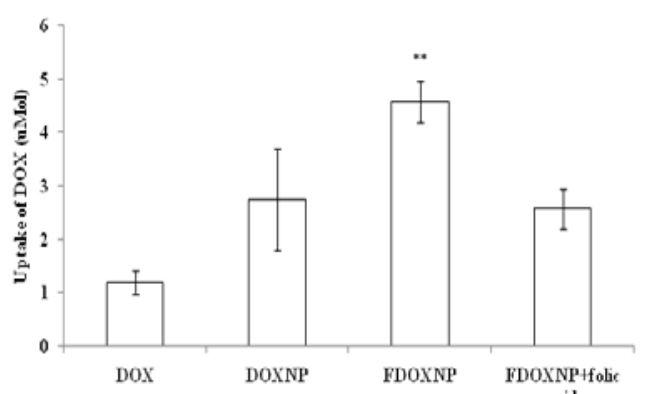

Figure 10: Quantitative uptake of DOX in SKOV3 cells using pure DOX, DOXNP (doxorubicin loaded unmodified nanoparticles), FDOXNP (doxorubicin loaded folate conjugated nanoparticles) and FDOXNP in presence of folic acid. ${ }^{* *} p$ $<0.05$.

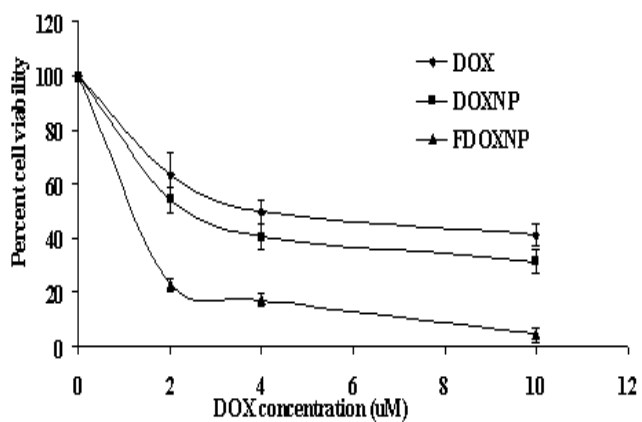

Figure 11: Cell viability studies of DOX in SKOV3 cells following treatment with DOX, DOXNP (doxorubicin loaded unmodified nanoparticles), FDOXNP (doxorubicin loaded folate conjugated nanoparticles) for $48 \mathrm{~h}$.

\section{Conclusion}

In summary, we have synthesized a PLGA-PEG-FOL polymer. Further, this polymer has been successfully employed in the preparation of folate conjugated DOX loaded nanoparticles (size $\sim 200 \mathrm{~nm}$ ) using SESE and DESE methods. Quantitative uptake and cell viability studies revealed that FDOXNP exhibited higher cellular uptake compared to pure DOX and DOXNP in SKOV3 cells overexpressing FRs. Hence, PLGA-PEG-FOL polymer can be used to target chemotherapeutic agents to tumor cells and thus reduce systemic toxicity. In vivo pharmacokinetic studies should be carried out to determine tumor suppression efficacy and biodistribution of folate conjugated nanoparticles.

\section{Acknowledgements}

The authors are thankful to Dr. Vladimir Dusevich, School of Dentistry, for helping with the operation of transmission electron microscopy and Dr. Elisabet Kostoryz, School of Dentistry, for helping us in dynamic light scattering studies. This work was supported by the National Institutes of Health grants R01 EY 0917114 and R01 EY 10659-12.

\section{References}

1. Langer R (2000) Biomaterials in drug delivery and tissue engineering: one laboratory's experience. Acc Chem Res 33: 94-101.

2. Pandey R, Khuller GK (2005) Antitubercular inhaled therapy: opportunities progress and challenges. J Antimicrob Chemother 55: 430-435.

3. Soppimath KS, Aminabhavi TM, Kulkarni AR, Rudzinski WE (2001) Biodegradable polymeric nanoparticles as drug delivery devices. J Control Release 70: 1-20.

4. Malaekeh-Nikouei B, Sajadi Tabassi SA, Jaafari MR (2006) The effect of different grades of PLGA on characteristics of microspheres encapsulated with cyclosporine A. Curr Drug Deliv 3: 343-349.

5. Shakesheff KM, Evora C, Soriano I I, Langer R (1997) The Adsorption of Poly(vinyl alcohol) to Biodegradable Microparticles Studied by X-Ray Photoelectron Spectroscopy (XPS). J Colloid Interface Sci 185: 538-547.

6. Zhao X, Li H, Lee RJ (2008) Targeted drug delivery via folate receptors. Expert Opin Drug Deliv 5: 309-319.

7. Gao X, Cui Y, Levenson RM, Chung LW, Nie S (2004) In vivo cancer targeting and imaging with semiconductor quantum dots. Nat Biotechnol 22: 969-976.

8. Jain KK (2005) Editorial: targeted drug delivery for cancer. Technol Cancer Res Treat 4: 311-313.

9. Park JW, Hong K, Kirpotin DB, Papahadjopoulos D, Benz CC (1997) Immunoliposomes for cancer treatment. Adv Pharmacol 40: 399-435.

10. Lu Y, Low PS (2002) Folate-mediated delivery of macromolecular anticancer therapeutic agents. Adv Drug Deliv Rev 54: 675-693.

11. Reddy JA, Allagadda VM, Leamon CP (2005) Targeting therapeutic and imaging agents to folate receptor positive tumors. Curr Pharm Biotechnol 6 : 131-150.

12. Goren D, Horowitz AT, Tzemach D, Tarshish M, Zalipsky S, et al. (2000) Nuclear delivery of doxorubicin via folate-targeted liposomes with bypass of multidrug-resistance efflux pump. Clin Cancer Res 6: 1949-1957.

13. Sudimack J, Lee RJ (2000) Targeted drug delivery via the folate receptor. Adv Drug Deliv Rev 41: 147-162.

14. Yoo HS, Park TG (2004) Folate receptor targeted biodegradable polymeric doxorubicin micelles. J Control Release 96: 273-283.

15. Sonvico F, Mornet S, Vasseur S, Dubernet C, Jaillard D, et al. (2005) Folateconjugated iron oxide nanoparticles for solid tumor targeting as potential specific magnetic hyperthermia mediators: synthesis, physicochemical characterization, and in vitro experiments. Bioconjug Chem 16: 1181-1188.

16. Labhasetwar V, Song C, Humphrey W, Shebuski R, Levy RJ (1998) Arteria uptake of biodegradable nanoparticles: effect of surface modifications. J Pharm Sci 87: 1229-1234.

17. Sahoo SK, Ma W, Labhasetwar V (2004) Efficacy of transferrin-conjugated paclitaxel-loaded nanoparticles in a murine model of prostate cancer. Int $J$ Cancer 112: 335-340.

18. Kim SH, Jeong JH, Chun KW, Park TG (2005) Target-specific cellular uptake of PLGA nanoparticles coated with poly(L-lysine)-poly(ethylene glycol)-folate conjugate. Langmuir 21: 8852-8857.

19. Patil YB, Toti US, Khdair A, Ma L, Panyam J (2009) Single-step surface 
Citation: Boddu SHS, Vaishya R, Jwala J, Vadlapudi A, Pal D, et al. (2012) Preparation and Characterization of Folate Conjugated Nanoparticles of Doxorubicin using Plga-Peg-Fol Polymer. Med chem 2: 068-075. doi:10.4172/2161-0444.1000117

functionalization of polymeric nanoparticles for targeted drug delivery. Biomaterials 30: 859-866.

20. Abraham, SA, Waterhouse, DN, Mayer, LD, Cullis, PR, Madden, TD, et al. (2005) The liposomal formulation of doxorubicin. Methods Enzymol 391: 71-97.

21. Carvalho C, Santos RX, Cardoso S, Correia S, Oliveira PJ, et al. (2009) Doxorubicin: the good, the bad and the ugly effect. Curr Med Chem 16: $3267-$ 3285.

22. Tewes F, Munnier E, Antoon B, Ngaboni Okassa L, Cohen-Jonathan S, et al. (2007) Comparative study of doxorubicin-loaded poly(lactide-co-glycolide) nanoparticles prepared by single and double emulsion methods. Eur J Pharm Biopharm 66: 488-492.

23. Boddu SH, Jwala J, Vaishya R, Earla R, Karla PK, et al. (2010b) Nove nanoparticulate gel formulations of steroids for the treatment of macular edema. J Ocul Pharmacol Ther 26: 37-48.

24. Boddu SH, Jwala J, Chowdhury MR, Mitra AK (2010a) In vitro evaluation of a targeted and sustained release system for retinoblastoma cells using Doxorubicin as a model drug. J Ocul Pharmacol Ther 26: 459-468.

25. Debotton N, Parnes M, Kadouche J, Benita S (2008) Overcoming the formulation obstacles towards targeted chemotherapy: in vitro and in vivo evaluation of cytotoxic drug loaded immunonanoparticles. J Control Release 127: 219-230.

26. Stella B, Arpicco S, Peracchia MT, Desmaële D, Hoebeke J, et al. (2000) Design of folic acid-conjugated nanoparticles for drug targeting. J Pharm Sci 89: $1452-1464$

27. Duvvuri, S, Janoria, KG, Mitra, AK (2005) Development of a novel formulation containing poly(d,I-lactide-co-glycolide) microspheres dispersed in PLGA-PEGPLGA gel for sustained delivery of ganciclovir. J Control Release 108: 282-293.

28. Choi SH, Park TG (2000) Hydrophobic ion pair formation between leuprolide and sodium oleate for sustained release from biodegradable polymeric microspheres. Int J Pharm 203: 193-202.

29. Duvvuri S, Gaurav Janoria K, Mitra AK (2006) Effect of polymer blending on the release of ganciclovir from PLGA microspheres. Pharm Res 23: 215-223.
30. Chittasupho C, Xie SX, Baoum A, Yakovleva T, Siahaan TJ, et al. (2009) ICAM1 targeting of doxorubicin-loaded PLGA nanoparticles to lung epithelial cells. Eur J Pharm Sci 37: 141-150.

31. Davda J, Labhasetwar V (2002) Characterization of nanoparticle uptake by endothelial cells. Int J Pharm 233: 51-59.

32. Esmaeili F, Ghahremani MH, Ostad SN, Atyabi F, Seyedabadi M, et al. (2008) Folate-receptor-targeted delivery of docetaxel nanoparticles prepared by PLGA-PEG-folate conjugate. J Drug Target 16: 415-423.

33. Yeung CK, Chan KP, Chan CK, Pang CP, Lam DS (2004) Cytotoxicity of triamcinolone on cultured human retinal pigment epithelial cells: comparison with dexamethasone and hydrocortisone. Jpn J Ophthalmol 48: 236-242.

34. Davis ME, Chen ZG, Shin DM (2008) Nanoparticle therapeutics: an emerging treatment modality for cancer. Nat Rev Drug Discov 7: 771-782.

35. Dube D, Francis M, Leroux JC, Winnik FM (2002) Preparation and tumor cel uptake of poly( $\mathrm{N}$-isopropylacrylamide) folate conjugates. Bioconjug Chem 13 685-692.

36. Choy JH, Jung JS, Oh JM, Park M, Jeong J, et al. (2004) Layered double hydroxide as an efficient drug reservoir for folate derivatives. Biomaterials 25 3059-3064.

37. Akasaka K, Gyimesi-Forrás K, Lämmerhofer M, Fujita T, Watanabe $M$, et al. (2005) Investigations of molecular recognition aspects related to the enantiomer separation of 2-methoxy-2-(1-naphthyl)propionic acid using quinine carbamate as chiral selector: An NMR and FT-IR spectroscopic as well as X-ray crystallographic study. Chirality 17: 544-555.

38. Yang SJ, Lin FH, Tsai KC, Wei MF, Tsai HM, et al. (2010) Folic acid-conjugated chitosan nanoparticles enhanced protoporphyrin IX accumulation in colorecta cancer cells. Bioconjug Chem 21: 679-689.

39. Pan L, Tong Y, Jin Y, Zhou S, Zhang Y, et al. (2001) Reversing drug resistance in the ovarian carcinoma cell line SKOV3/mdr1 in vitro by antisense oligodeoxynucleotides. Chin Med J (Engl) 114: 929-932.

40. Kartner N, Evernden-Porelle D, Bradley G, Ling V (1985) Detection of $\mathrm{P}$-glycoprotein in multidrug-resistant cell lines by monoclonal antibodies. Nature 316: 820-823. 